\title{
Mechanisms and Therapeutic Implications of Neuroleptic Atypicality
}

\author{
Daniel C. Javitt, MD \\ Albert Einstein School of Medicine
}

Follow this and additional works at: https://jdc.jefferson.edu/jeffjpsychiatry

Part of the Psychiatry Commons

Let us know how access to this document benefits you

\section{Recommended Citation}

Javitt, MD, Daniel C. (1989) "Mechanisms and Therapeutic Implications of Neuroleptic Atypicality," Jefferson Journal of Psychiatry. Vol. 7 : Iss. 1 , Article 4.

DOI: https://doi.org/10.29046/JJP.007.1.001

Available at: https://jdc.jefferson.edu/jeffjpsychiatry/vol7/iss1/4

This Article is brought to you for free and open access by the Jefferson Digital Commons. The Jefferson Digital Commons is a service of Thomas Jefferson University's Center for Teaching and Learning (CTL). The Commons is a showcase for Jefferson books and journals, peer-reviewed scholarly publications, unique historical collections from the University archives, and teaching tools. The Jefferson Digital Commons allows researchers and interested readers anywhere in the world to learn about and keep up to date with Jefferson scholarship. This article has been accepted for inclusion in Jefferson Journal of Psychiatry by an authorized administrator of the Jefferson Digital Commons. For more information, please contact: JeffersonDigitalCommons@jefferson.edu. 


\title{
Mechanisms and Therapeutic Implications of Neuroleptic Atypicality
}

\author{
Daniel C. Javitt, M.D.
}

\section{PRECIS}

Neuroleptics have proven effective for the overall treatment of schizophrenia. The neuroleptic therapy of schizophrenia, however, has been limited by tardive dyskinesia and by the relative inability of neuroleptics to ameliorate the negative symptoms of schizophrenia. Intensive research has been conducted to identify atypical neuroleptics which would not cause TD and which would have relatively greater efficacy in treating negative symptoms. Based upon animal models of TD and negative symptoms, four neuroleptics have been identified which may have these properties: clozapine, thioridazine, sulpiride, and molindone. Clinical studies of TD suggest that these four potentially atypical agents may have lower dyskinetic potential than typical neuroleptics. Additionally, clinical studies of negative symptoms suggest that molindone and sulpiride, but not clozapine or thioridazine may preferentially treat depressive-like negative schizophrenic symptomatology. The atypical effects of clozapine, thioridazine, sulpiride and molindone, suggest that they may have a distinct place in the pharmacotherapy of schizophrenia.

\section{INTRODUCTION}

Since their discovery in the mid-1950s, neuroleptic drugs have proven to be safe and effective treatments for schizophrenia. Schizophrenic subjects treated with neuroleptics have been shown to have improved overall functioning and a decreased need for hospitalization versus non-treated controls. The pharmacotherapy of schizophrenia with neuroleptics, however, has proven to be limited by at least two factors. First, neuroleptics increase the rate at which schizophrenic patients develop the long-term potentially irreversible and incapacitating movement disorder, tardive dyskinesia (TD). Second, neuroleptics have proven relatively ineffective in treating the negative symptoms of schizophrenia (e.g. blunted affect, poverty of speech and of ideation) $(1,2)$ and may induce akinetic symptoms which closely resemble the negative schizophrenic symptoms $(3,4)$. Intensive research has been conducted over the past three decades on both a basic science and a clinical level to determine whether or not these two limitations are inevitable concomitants of neuroleptic therapy. Basic studies using animal models of TD and negative symptoms now suggest that several agents do behave differently from traditional neuroleptics (e.g. chlorpromazine, haloperidol) and may indeed possess atypical clinical properties 
including a relatively decreased dyskinetogenic potential and/or a relatively increased efficacy in treating negative symptoms. Four such potentially atypical agents have been identified. Clozapine, a compound of the dibenzodiazepine class, has been the best studied and is considered the prototype atypical neuroleptic. Long-term clinical studies have suggested that clozapine has low to absent dyskinetogenic potential. Clozapine, however, remains available in this country only on an experimental basis because of associated agranulocytosis. Thioridazine, a widely used neuroleptic of the piperidine phenothiazine class, appears to have clozapine-like effects in basic models of TD although to a more limited extent. Detailed clinical studies have not been conducted that would allow a determination of the dyskinetogenic potential of thioridazine. Cases of TD presumably related to thioridazine treatment have been reported and the possible decreased dyskinetogenic potential of thioridazine has been much debated $(5,6)$. Sulpiride, a substituted benzamide, and molindone, an indolic derivative, are other neuroleptics with novel chemical structures. These agents, at least in some dose ranges, behave similarly to clozapine in basic models of TD. While definitive clinical studies have yet to be performed for these agents, studies using masking paradigms suggest that these agents also may have decreased dyskinetogenic potential compared with traditional neuroleptics. Sulpiride and molindone behave differently from traditional neuroleptics in animal models of negative symptoms as well, suggesting that they may also have improved efficacy in treating negative symptoms.

\section{BASIC STUDIES}

The role of dopaminergic hyperactivity in schizophrenic pathophysiology has now been well established. Agents which increase brain dopaminergic transmission worsen overall schizophrenic symptomatology. The potency with which neuroleptic agents ameliorate schizophrenic symptoms correlates with their potency in blocking dopaminergic transmission at $\mathrm{D}_{2}$ type dopamine receptors $(7,8)$. Less well established, however, is the role of the various brain dopaminergic systems in contributing to schizophrenic pathophysiology and the clinical response to neuroleptics. Three separate dopaminergic systems have been identified in forebrain. Two of these, the mesocortical and mesolimbic systems arise from the midbrain ventral tegmental area (area A10) and innervate the neocortex (e.g. frontal cortex, cingulate cortex) and limbic system (e.g. nucleus accumbens) respectively. The third arises from the substantia nigra (area A9) and innervates the neostriatum. The mesocortical and mesolimbic systems are thought to subserve cognition and affective regulation while the nigrostriatal system, which has been implicated in the pathophysiology of Parkinson's disease (9) and Huntington's chorea (10), is thought to be involved mainly with regulation of brain motoric systems. The therapeutic actions of neuroleptics and their behavioral side effects may result primarily from their actions in the mesolimbic and mesocortical systems while the dyskinetogenic 
effects of neuroleptics are likely to be mediated by their actions on the nigrostriatal system $(7,8)$. As a result, agents which selectively spare the nigrostriatal system should have a relatively decreased risk of inducing TD. Several model systems have been used in an attempt to measure the effects of neuroleptics on the mesocortical and mesolimbic systems versus their effects on the nigrostriatal system. Three of these paradigms in particular have gained widespread acceptance (Table 1). Studies using these paradigms suggest that the proposed atypical agents clozapine, thioridazine, sulpiride, and molindone induce less inhibition of nigrostriatal dopaminergic transmission than traditional agents. These agents, therefore, might have a relatively decreased risk for inducing motoric side effects and, in particular, TD.

\section{Behavioral Supersensitivity}

The first model of TD is based upon the observation that in rats the dopaminergic agent amphetamine produces a characteristic syndrome of stereotypies and hyperactivity. Amphetamine-induced stereotypies have been shown to be mediated by the nigrostriatal system while amphetamine-induced hyperactivity is mediated by the mesolimbic system $(11,12)$. Typical neuroleptic agents

TABLE 1.

Summary of Animal Models for Tardive Dyskinesia

\begin{tabular}{|c|c|c|c|}
\hline Paradigm & & Typical Neuroleptics & Atypical Neuroleptics \\
\hline \multirow[t]{2}{*}{$\begin{array}{l}\text { Behavioral } \\
\text { supersensitivity }\end{array}$} & acute: & $\begin{array}{l}\downarrow \text { ampetamine induced } \\
\text { hyperactivity } \\
\downarrow \text { amphetamine induced } \\
\text { stereotypy }\end{array}$ & $\begin{array}{l}\downarrow \text { amphetamine induced } \\
\text { hyperactivity } \\
\text { N.C. amphetamine in- } \\
\text { duced stereotypy }\end{array}$ \\
\hline & chronic: & $\begin{array}{l}\uparrow \text { amphetamine induced } \\
\text { stereotypy } \\
\uparrow \text { amphetamine induced } \\
\text { stereotypy }\end{array}$ & $\begin{array}{l}\uparrow \text { amphetamine induced } \\
\text { stereotypy } \\
\text { N.C. amphetamine in- } \\
\text { duced stereotypy }\end{array}$ \\
\hline $\begin{array}{l}\text { Receptor } \\
\quad \text { supersensitivity }\end{array}$ & chronic: & $\begin{array}{l}\uparrow \text { receptor density - nu- } \\
\text { cleus accumbens } \\
\uparrow \text { receptor density - stria- } \\
\text { tum }\end{array}$ & $\begin{array}{l}\uparrow \text { receptor density - nu- } \\
\text { cleus accumbens } \\
\text { N.C. receptor density } \\
\text { striatum }\end{array}$ \\
\hline \multirow[t]{2}{*}{$\begin{array}{c}\text { Depolarization } \\
\text { inactivation }\end{array}$} & acute: & $\begin{array}{l}\uparrow \text { firing rate }-\mathrm{A} 9 \\
\uparrow \text { firing rate }-\mathrm{A} 10\end{array}$ & $\begin{array}{l}\text { N.C. or } \downarrow \text { firing rate - A9 } \\
\uparrow \text { firing rate - A } 10\end{array}$ \\
\hline & chronic: & $\begin{array}{l}\downarrow \text { firing rate - A9 } \\
\downarrow \text { firing rate - A } 10\end{array}$ & $\begin{array}{l}\text { N.C. firing rate }- \text { A9 } \\
\downarrow \text { firing rate }-\mathrm{A} 10\end{array}$ \\
\hline
\end{tabular}

Effects of acute and chronic treatments with typical and atypical neuroleptics on amphetamine-induced hyperactivity and stereotypies, on dopamine receptor density in nucleus accumbens and striatum and on the firing rate of neurons in A9 and A10 midbrain dopaminergic nuclei. N.C. indicates no change. 
acutely block both amphetamine-induced stereotypies and hyperactivity suggesting that they induce a net dopaminergic blockade in both the nigrostriatal and the mesolimbic systems. The prototypical atypical agent clozapine, conversely, inhibits only amphetamine-induced hyperactivity while paradoxically enhancing amphetamine-induced stereotypies (13-17). Clozapine, therefore, appears to block dopaminergic transmission only in the mesolimbic system while sparing or possibly enhancing nigrostriatal dopaminergic transmission. Thioridazine (16-18), sulpiride (13,16,17,19-21) and molindone (22) also potentiate amphetamine-induced stereotypies suggesting that these agents also spare nigrostriatal system functioning.

Following chronic treatment with typical neuroleptic agents, rats show an increased sensitivity for developing amphetamine-induced stereotypies and hyperactivity. This increased sensitivity is thought to result from a compensatory supersensitivity of nigrostriatal and mesolimbic dopaminergic receptors following prolonged blockade. In contrast to typical agents, clozapine has been shown to induce supersensitivity only of amphetamine-induced hyperactivity and not of amphetamine-induced sterotypies $(14,15)$ suggesting that it does not induce long-term changes in nigrostriatal system functioning. Thioridazine (23), sulpiride (19) and molindone $(24,25)$ either do not induce supersensitivity to amphetamine-induced stereotypies in rats following chronic treatment or do so with considerably less potency than equivalent dosages of traditional agents. While a relationship between behavioral supersensitivity to amphetamine and TD has yet to be demonstrated, the relative ability of these proposed atypical agents to spare the nigrostriatal system suggests that these agents may be less likely than typical agents to induce long-term changes in the nigrostriatal system.

\section{Receptor Supersensitivity}

In order to investigate whether dopamine receptor supersensitivity underlies the neuroleptic-induced behavioral supersensitivity, dopamine receptors in the striatum and nucleus accumbens have been studied directly using radiolabelled agents which bind specifically to $D_{2}$-type dopamine receptors (e.g. $\left[{ }^{3} \mathrm{H}\right]$ spiperone). Traditional neuroleptics have been shown to induce an increase in the number of $\mathrm{D}_{2}$ receptors in the striatum following days to weeks of continuous treatment. By contrast clozapine $(14,15,26)$, sulpiride $(26,27)$ and molindone (24) do not induce supersensitivity of striatal $\mathrm{D}_{2}$ receptors, suggesting again that these agents affect nigrostriatal dopaminergic transmission to a lesser extent than traditional agents do.

Shortly after the discovery of neuroleptic-induced supersensitivity of striatal $D_{2}$ receptors it was proposed that dyskinetic movements result from the interaction of endogenous dopamine with the supersensitive $D_{2}$ receptors $(28,29)$. Recent findings, however, have called this theory into question $(30)$. First, receptor supersensitivity can develop after a single administration of 
neuroleptics whereas dyskinetic symptoms arise only after prolonged administration. Second, receptor supersensitivity develops in all subjects tested, while TD develops sporadically. Third, receptor supersensitivity remains reversible upon withdrawal of neuroleptics while TD may persist indefinitely. Finally, detailed post-mortem studies have failed to find an association between striatal $D_{2}$ receptor density and a prior history of TD (31). $D_{2}$ receptor supersensitivity, therefore, is probably not mechanistically related to TD. Receptor supersensitivity may however be seen as a step in the cascade of events which ultimately results in the expression of dyskinetic symptoms.

\section{Depolarization Inactivation}

In addition to their behavioral and biochemical effects, neuroleptics have been shown to directly affect the firing patterns of dopaminergic neurons in the A9 and A10 midbrain nuclei, which originate in the nigrostriatal and mesolim$\mathrm{bic} /$ mesocortical pathways respectively. Blockade of dopaminergic transmission depolarizes neurons in both the A9 and A 10 nuclei, leading to an acute increase in their firing rate (32). Following chronic neuroleptic-induced depolarization, however, these neurons gradually lose their coordinated pattern of firing and over time become completely quiescent. Direct administration of $\gamma$-aminobutyric acid (GABA), an inhibitory transmitter, can restore activity to these inactivated neurons suggesting that their inactivation is due to chronic depolarization (33). Neuroleptic-induced depolarization of A10 neurons is thought to underlie the antipsychotic effects of neuroleptics and possibly their behavioral side effects while doplarization inactivation of A9 neurons may be the first step in a sequence of events leading to TD (34). In this theory (35), it is hypothesized that blockade of postsynaptic striatal dopamine receptors leads to a decrease in the activity of the normally inhibitory GABA-mediated striatonigral feedback pathway which leads to a depolarization of A9 neurons and an acute increase of striatal dopamine release. Following prolonged dopaminergic blockade, however, the A9 neurons become incapable of sustaining the increased firing rate and become gradually inactive leading to a decline in striatal dopamine release. As long as the striatonigral GABAergic neurons remain intact, the process remains reversible. Dopaminergic denervation of the GABAergic neurons, however, appears to place an adaptive stress upon them which over time may facilitate their degeneration. Degeneration of GABAergic striatonigral neurons has been implicated in the pathophysiology of Huntington's chorea (10) and Wilson's disease, conditions which present with dyskinetic symptoms clinically indistinguishable from those of TD, and so may be the final common pathway for the generation of dyskinetic movements. Experimental destruction of the striatonigral pathway in animals leads to depolarization inactivation in A9 and to the development of dyskinetic movements (36). Cebus monkeys who are exposed to neuroleptics over a period of years can develop dyskinesias which closely resemble those of TD (37). Monkeys who develop dyskinesias have been shown 
to have significantly lower levels of GABA in the substantia nigra than monkeys who do not (38) suggesting that a failure of GABAergic neurons to adapt to functional dopaminergic denervation may be etiologically related to the development of dyskinesias. Human post-mortem studies of schizophrenics have likewise demonstrated a decreased striatal GABA level in subjects with a prior history of TD versus those without (31). No differences in dopamine receptor numbers were found in these patients. These findings suggest that while depolarization inactivation of A9 neurons does not directly underlie dyskinetic movements. It may be the first of a cascade of events which ultimately results in TD. Agents which do not induce depolarization inactivation of A9 neurons, therefore, should be relatively without dyskinetogenic potential.

Administration of the traditional neuroleptics chlorpromazine, haloperidol and fluphenazine has been shown to lead to an acute increase in the firing rate of neurons in both $\mathrm{A} 9$ and A 10 followed by a sustained depolarization inactivation of these neurons (39-41). By contrast, clozapine $(33,39,40)$, thioridazine (39), sulpiride (39) and molindone (39) have been shown not to induce depolarization inactivation in A9. Acute administration of these agents increases the firing rate of neurons in A10 but not in A9 while their chronic administration leads to a decrease in the firing rates of neurons only in A 10. Clozapine and molindone (41) have also been shown to reverse the inhibition of firing rates induced by chronic haloperidol at the dosages used in these studies. Clozapine, thioridazine, sulpiride and molindone therefore, appear not to inhibit nigrostriatal dopaminergic transmission and so may be less likely than traditional agents to induce TD. 1-Sulpiride, the "active" isomer of sulpiride, has been shown to induce depolarization inactivation of A9 when administered on its own whereas d-sulpiride, the "inactive" isomer, has no effect (33). For sulpiride, therefore, atypicality may depend upon administering racemate l-sulpiride which is the clinically available form of the drug.

\section{Possible Mechanisms of Neuroleptic Atypicality}

The exact mechanism by which atypical neuroleptics spare the nigrostriatal system remains a question of intense debate. One common ability of all putative atypicals is to selectively increase presynaptic dopamine release in the striatum. Presynaptic dopamine synthesis and release can be assayed either by measuring the activity of tyrosine hydroxylase, the rate limiting enzyme responsible for dopamine synthesis, or by directly measuring the levels of dopamine metabolites. Using these assays, it has been found that clozapine, thioridazine, sulpiride and molindone all increase dopamine synthesis and release in the striatum but that they differ in the mechanism by which they do so. Clozapine and thioridazine have been found to stimulate tyrosine hydroxylase activity via nonhaloperidol sensitive receptors (43) and to increase DA metabolite levels via a transsynaptic mechanism (44). Molindone (44) and sulpiride (45), conversely, appear to operate via a homosynaptic mechanism. The atypical effects of 
clozapine and thioridazine, therefore, are probably mediated via their actions on the non-dopaminergic brain systems which regulate dopaminergic transmission while the atypical effects of molindone and sulpiride are most probably mediated via their direct effects on the dopaminergic terminals.

Clozapine and to a lesser extent thioridazine have been shown to have relatively low potencies of action at brain $\mathrm{D}_{2}$ receptors and relatively high potencies at $\mathrm{D}_{1}$ dopaminergic receptors, at adrenergic receptors, at muscarinic cholinergic receptors and at serotonergic receptors $(46,47)$. It remains unclear which if any of these receptors mediates the atypical effects of clozapine and thioridazine. Most attention has been focused upon anti-cholinergic and antiadrenergic effects $(48,49)$. More recently it has been suggested that the antiseritonergic potency of clozapine may contribute to its atypicality as well. In one study, LSD, a serotonergic agonist, potentiated the hyperactivity induced by the dopaminergic agent apomorphine. Clozapine but not haloperidol or sulpiride inhibited the LSD-induced potentiation of apomorphine hyperactivity $(50)$ suggesting that clozapine has a distinct effect on brain serotonergic systems when compared with other neuroleptics. Thioridazine was not explicitly tested in this paradigm. Striatum (51) and substantia nigra (32) receive innervation from brain serotonergic systems suggesting that serotonin may play a modulatory role in nigrostriatal system functioning. The mechanism by which clozapine's anti-serotonergic effects might result in a decreased dyskinetic potential, however, remains to be determined.

By contrast to clozapine and thioridazine, molindone and sulpiride bind extremely weakly to $\mathrm{D}_{1}$ receptors, to muscarinic cholinergic receptors, to adrenergic receptors and to serotonergic receptors $(46,47)$. Both molindone and sulpiride, however, bind potently to a class of dopamine receptors called dopamine autoreceptors (DARs). DARs respond directly to pre-synaptically released dopamine and serve to inhibit further dopamine release. Blockade of this negative feedback system effectively increases the rate of pre-synaptic dopamine synthesis and release (52). Low dose apomorphine $(<0.4 \mathrm{mg} / \mathrm{kg})$ selectively stimulates DARs (53). Using apomorphine to assess DAR functioning, it has been found that molindone inhibits DARs 2-4 times more potently than post-synaptic receptors. In the dose range of $1-3 \mathrm{mg} / \mathrm{kg}$, molindone preferentially inhibits DARs (22,54-56). Sulpiride has also been shown to preferentially inhibit DARs, at doses up to $10 \mathrm{mg} / \mathrm{kg}(21,53)$. Clozapine and thioridazine, as opposed to molindone and sulpiride, appear to antagonize DAR-mediated activities extremely weakly $(53,54)$. DARs have been shown to regulate dopamine release in the nigrostriatal system (59). Agents which act preferentially on DARs, therefore, would be expected not to inhibit and possibly to enhance dopaminergic neurotransmission in the striatum. Such an effect could underlie the atypical effects of molindone and sulpiride in animal models of TD. It should be noted, however, that at high doses molindone and sulpiride can effectively block postsynaptic dopamine receptors. At high doses, therefore, these agents might be expected to behave similarly to traditional neuroleptics. 
In addition to regulating nigrostriatal functioning, DARs regulate mesolimbic dopaminergic transmission $(52,60,61)$. Stimulation of postsynaptic dopamine receptors with amphetamine or high dose apomorphine has been shown to induce motor hyperactivity which is mediated via the mesolimbic system. Low dose apomorphine, conversely, binds preferentially to DARs, leading to decreased mesolimbic dopamine release and a characteristic syndrome of hypomotility and sedation in rodents (53). Neither clozapine nor thioridazine reverses the hypomotility induced by low dose apomorphine (53). These agents, therefore, appear to have little ability to reverse mesolimbic dopaminergic blockade. Conversely sulpiride has been shown to inhibit apomorphine-induced hypomotility (53) suggesting that it may not induce net dopaminergic underactivity in the mesolimbic system when administered alone. While the effect of molindone on hypomotility has not been explicitly tested, molindone has been shown to inhibit the effects of low dose apomorphine on dopamine release $(54,56)$ and so would be expected to share sulpiride's behavioral effects.

The relationship between apomorphine-induced hypomotility and schizophrenic symptomatology remains to be determined. In one study (62), however, it was shown that apomorphine-induced hypomotility is accompanied by a reward deficit in rats. Untreated rats show an ability to increase their rate of bar pressing when they are shifted from a schedule in which they are rewarded with a food pellet for each response to one in which they are rewarded for only every fourth response. After three sessions untreated rats are able to obtain the same number of pellets as before the shift in reward schedule. Rats pretreated with low dose apomorphine, however, fail to significantly alter their rate of responding following the shift in reward schedule. Since the rats remain physically capable of increasing their responding rate, this failure of responding may represent a decreased responsiveness to secondary reinforcers. It was proposed that this decreased responsiveness might represent a model for depressive-like negative schizophrenic symptoms such as anhedonia and emotional withdrawal. Sulpiride completely reverses the reward deficit induced by apomorphine. Thioridazine, haloperidol, chlorpromazine and fluphenazine by contrast fail to reverse the apomophine-induced reward deficit at any dose. Molindone has not been explicitly tested in this paradigm.

In man, the mesolimbic system appears to regulate behavioral activity and mood. Low dose apomorphine produces sedation and sleep and may precipitate severe depression (63). Underactivity of the mesolimbic system appears to be involved in the psychomotor retardation and poor environmental reactivity seen in patients with Parkinson's disease (9) and endogenous depression $(64,65)$. Furthermore, based upon animal models, it has been postulated that DARhypersensitivity, leading to diminished mesolimbic dopamine release, might be etiologic in some forms of retarded depression (66). The role of DARs in humans, therefore, may be similar to their role in rodents. The ability of 
molindone and sulpiride to preferentially block DARs might predict that these agents could preferentially treat the depressive-like negative symptoms including psychomotor retardation and emotional withdrawal.

\section{CLINICAL STUDIES}

While the basic models of TD and negative symptoms suggest that clozapine, thioridazine, sulpiride and molindone may produce atypical clinical effects, ultimate confirmation or refutation of these predictions can only be obtained from detailed clinical studies. Since TD generally develops 1-2 years after the initiation of neuroleptic therapy and occurs only in a minority of subjects (66), definitive comparison of the relative dyskinetogenic potential of neuroleptics requires long-term longitudinal studies of first break schizophrenic patients spanning several years and involving large numbers of subjects. Of the four neuroleptics which show atypical effects in animal models, only clozapine has been subjected to sufficient study to suggest that it has significantly lower dyskinetogenic potential than traditional agents. In one study of 216 psychiatric patients treated with clozapine as sole neuroleptic for up to 12 years no cases of TD were reported (67). Other studies have similarly shown a decreased dyskinetic potential for clozapine (68). Thioridazine, sulpiride and molindone, by contrast, have not been subjected to sufficiently long-term studies to allow an estimation of their dyskinetic potential versus traditional agents.

In the absence of long-term longitudinal studies of schizophrenic patients, “masking" paradigms have been used to try to study the relative dyskinetogenic potentials of neuroleptic agents. In this approach, subjects are chosen who have developed persistent withdrawal exacerbated TD. These subjects are assigned to different neuroleptic regimens and the potency with which these agents mask dyskinetic symptoms is determined. Based upon animal studies $(37,69,70)$, it has been proposed that those agents which are least potent in masking dyskinetic symptoms should be least likely to induce de novo TD. In a closely related paradigm, subjects with preexisting TD are exposed to neuroleptics and the post- vs. pre-exposure severity of TD is determined. Studies using these paradigms have been conducted with haloperidol and with the proposed atypicals clozapine, thioridazine and molindone. Active treatment with haloperidol has been shown to potently mask dyskinetic symptoms. Subsequent withdrawal of haloperidol leads to a rebound worsening of dyskinetic symptoms suggesting that a progression of the underlying process has occured (69-76). Clozapine, by contrast, has been shown to have no significant antidyskinetic effects and withdrawal of clozapine does not lead to rebound worsening $(70,71)$. Thioridazine (70) and molindone (72) also mask dyskinetic symptoms less potently than haloperidol does. These agents, however, do produce a significant degree of masking and therefore cannot be considered free of dyskinetogenic potential. While sulpiride has been shown in humans to have some ability to mask dyskinetic symptoms $(73,74)$, its potency has not been directly compared 
either to traditional neuroleptics or to other atypicals. In Cebus monkeys with persistent neuroleptic-induced orofacial dyskinesias sulpiride has been shown to mask dyskinetic movements to a lesser degree than either haloperidol or fluphenazine (75). In addition to clozapine, thioridazine (70) and sulpiride (75) do not induce rebound worsening of TD. Additionally, clozapine and thioridazine have also been found not to induce rebound worsening in Cebus monkeys with persistent dyskinesias (76). Molindone has not been directly tested in the rebound worsening paradigm. These studies support the basic prediction that clozapine, thioridazine, sulpiride and molindone have relatively decreased dyskinetogenic potential when compared with traditional agents. Only clozapine, however, appears inactive in these paradigms, suggesting that the other three agents might still have significant although decreased risks of associated TD. Furthermore, although thioridazine does not produce rebound worsening of TD in monkeys, two of its metabolites, mesoridazine and sulforidazine, have been shown to induce rebound worsening while a third metabolite, thioridazine ring sulfoxide, does not (69). Individual metabolism may therefore affect whether thioridazine and possibly other neuroleptics have decreased dyskinetogenic potential in any given subject.

Negative symptoms have also proven difficult to study clinically. No definitive studies have been conducted which either support or refute the suggestion that sulpiride and molindone should be more efficacious than other neuroleptics in treating negative symptoms. Difficulties arise because negative symptoms have proven difficult both to define and operationalize. In the last few years, however, phenomenological studies have demonstrated that depressivelike negative symptoms (e.g. fatigue, blunted affect and loss of interest) constitute a cluster of symptoms which are distinct from either positive or hebephrenic-like negative symptoms $(77,78)$. The separate clustering of these symptoms suggests that they may be etiologically distinct from other symptoms of schizophrenia and may possibly be mediated by different brain pathways. Operationalized criteria for negative symptoms have been proposed only within the last few years $(79,80)$. Since no studies have directly compared neuroleptics using well validated negative symptom scales, no firm conclusions can be drawn concerning the relative effectiveness of typical and atypical neuroleptics in treating negative symptoms. Preliminary conclusions can be drawn, however, from medication trials which utilized the Brief Psychiatric Rating Scale (BPRS) (81). Three BPRS items, emotional withdrawal, blunted affect, and motor retardation have been found to correlate with negative symptoms scores but not with positive symptoms suggesting that they might be useful post-hoc measures of negative symptomatology $(77,82)$. These symptoms are commonly combined to form the withdrawal/retardation subscale (81).

In reviewing three studies (83-85) which compared clozapine either to baseline or to reference neuroleptic (chlorpromazine or haloperidol), clozapine significantly improved symptoms of withdrawal and retardation in two of the three. In none of these studies, however, were the differences significant versus 
a reference neuroleptic. In a fourth study, clozapine failed to improve any of the BPRS negative symptoms (86). Perhaps most indicative of the effects of clozapine are the results of a large multicenter European study (87) in which clozapine was compared with three reference neuroleptics. While clozapine was effective overall in treating BPRS negative symptoms, no clear differential effect was observed. In one substudy, clozapine was superior to chlorpromazine in the treatment of withdrawal/retardation. The differential effect, however, was less than for hyperactivity and core symptoms, however, suggesting that clozapine's superiority was global rather than restricted to negative symptoms.

Thioridazine and its active metabolite mesoridazine have similarly been compared with reference neuroleptics in a number of studies. In three studies (88-90), thioridazine has been shown to be relatively ineffective in ameliorating emotional withdrawal and psychomotor retardation. Mesoridazine, its active metabolite, has been shown to be somewhat more effective in the treatment of negative symptoms (89-93) possibly because it is less sedating. Mesoridazine also, however, has been found not to be significantly better than reference in treating negative symptoms. Moreover, in one study in which all BPRS symptoms improved significantly following treatment with mesoridazine, blunted affect and emotional withdrawal showed the least improvement (93).

Sulpiride has been relatively poorly studied in trials which employ the BPRS. In three such studies (94-96), sulpiride was found to consistently ameliorate emotional withdrawal, motor retardation and emotional blunting along with the subscale anergia, although in none of these studies was sulpiride significantly superior to the reference neuroleptic (haloperidol). However, in one study which used the Comprehensive Psychopathological Rating Scale (CPRS) to compare sulpiride versus cholorpromazine (97), sulpiride was found to be significantly superior to chlorpromazine in the treatment of autistic symptoms. These symptoms which consisted of inability to feel, lassitude, withdrawal, reduced speech and slowness of movement are analogous to BPRS defined negative symptoms but have not been directly validated against them. While sulpiride and chlorpromazine both produced significant improvement in global symptomatology and in positive symptoms, sulpiride significantly decreased autistic symptoms whereas chlorpromazine did not. Of interest, sulpiride-induced improvement in negative symptoms was found to be inversely correlated with sulpiride drug concentration such that those subjects with the highest serum sulpiride concentrations were found to have the least improvement in negative symptoms. Moreover, no significant correlation was found between serum levels of either sulpiride (or chlorpromazine) and positive schizophrenic symptoms. Since the dosage of sulpiride used in the last study $(800$ $\mathrm{mg} /$ day) was significantly less than the dosages in the three studies employing the BPRS (1200-1600 $\mathrm{mg} / \mathrm{d}$ mean final dosage) the differences in outcome might be related to the dosage differences. Two other uncontrolled studies have also suggested that sulpiride may have anti-autistic effects at dosages of $800(98)$ and 600-1200 (99) $\mathrm{mg} /$ day. These studies, therefore, suggest that low dose 
sulpiride may have relatively improved efficacy in treating negative symptoms although at high doses this differential effect may be lost.

Of 16 clinical trials with molindone, 7 have compared it to a reference neuroleptic using the BPRS (100-106). Of these, six demonstrated improvement either in the items; emotional withdrawal, motor retardation and blunted affect or in the withdrawal/retardation subscale which encompasses these items. Of the four studies which measured the withdrawal/retardation subscale explicitly (103-106), all four demonstrated a significant response of these symptoms to molindone but not to reference neuroleptic. In three of these studies, the preferential effects of molindone on negative symptoms were statistically significant. These studies support the prediction based upon animal models that molindone may be superior to traditional neuroleptics in the treatment of negative symptoms.

\section{THERAPEUTIC IMPLICATIONS}

These clinical studies support the animal model-based predictions that clozapine, thioridazine, molindone, and sulpiride may have relatively decreased dyskinetogenic potential compared with traditional agents. Only clozapine, however, appears completely free of associated TD. Of the four atypical agents, only two, thioridazine and molindone, are currently available for nonexperimental use in the U.S. These agents appear to differ in the mechanism of their atypicality and in their clinical effects. Thioridazine which is a relatively sedating neuroleptic with no apparent specific efficacy in treating negative symptoms appears to be more clozapine-like in its mechanism of atypicality. Molindone, conversely, more closely resembles the proposed atypical agent sulpiride and appears to produce atypical clinical effects by virtue of its ability to selectively block presynaptic dopamine autoreceptors (DARs). Molindone, like sulpiride, has been shown to be relatively more effective in treating negative symptoms of schizophrenia than traditional neuroleptics. A theoretical concern with molindone is that, like sulpiride, it may lose its atypicality at high dosages. In animal studies, molindone has been shown to lose some degree of atypicality at dosages over $3 \mathrm{mg} / \mathrm{kg}(24,25)$. Whether a similar therapeutic window exists clinically remains to be determined.

\section{REFERENCES}

1. Angrist B, Rotrosen J, Gershon S: Differential effects of amphetamine and neuroleptics on negative vs. positive symptoms in schizophrenia. Psychopharmacol 72:17-19, 1980

2. Andreasen NC: Negative syndrome in schizophrenia: Strategies for long-term management, in Chronic Treatment in Neuropsychiatry. Edited by Kemali D, Racagni G. New York, Raven Press, 1985

3. Rifkin A, Quitkin F, Kane J, et al: Are prophylactic antiparkinson drugs necessary? Arch Gen Psychiatry 35:483-489, 1978 
4. Rifkin A, Quitkin F, Klein DF: Akinesia. Arch Gen Psychiatry 32:672-674, 1975

5. Tardive dyskinesia and thioridazine [letter]. Arch Gen Psychiatry 41:414-416, 1984

6. On Sandoz's claim of thioridazine's comparative safety [letter]. Am J Psychiatry 140:1645-1648, 1983

7. Carlsson A: Antipsychotic drugs, neurotransmitters, and schizophrenia. Am J Psychiatry 135:164-173, 1978

8. Hornykiewicz O: Psychopharmacological implications of dopamine and dopamine antagonists: a critical evaluation of current evidence. Neurosci 3:773-783, 1978

9. Price KS, Farley IJ, Hornykiewicz O: Neurochemistry of Parkinson's disease: Relation between striatal and limbic dopamine. Adv Biochem Psychopharmacol 19:293-300, 1978

10. McGeer PL, McGeer EG: The GABA system and function of the basal ganglia: Huntington's disease, in GABA in Nervous System Function. Edited by Roberts E, Chase TN, Tower DB. New York, Raven Press, 1976

11. Costall B, Naylor RJ, Cannon JG, Lee T: Differentiation of the dopamine mechanism mediating stereotyped behiour and hyperactivity in the nucleus accumbens and caudate putamen. J Pharm Pharmacol 29:337-342, 1977

12. Kelly PH, Seviour PW, Iversen SD: Amphetamine and apomorphine responses in the rat following 6-OHDA lesions of the nucleus accumbens septia and corpus striatum. Brain Res 94:507-522, 1975

13. Robertson A, MacDonald C: Atypical neuroleptics clozapine and thioridazine enhance amphetamine-induced stereotypy. Pharmacol Biochem Behav 21:97-101, 1984

14. Seeger TF, Thal L, Gardner E: Behavioral and biochemical aspects of neuroleptic induced dopaminergic supersensitivity: Studies with chronic clozapine and haloperidol. Psychopharmacol 76:182-7, 1982

15. Rupniak NMJ, Hall MD, Mann S, Fleminger S, Kilpatrick G, Jenner P, Marsden $\mathrm{CD}$ : Chronic treatment with clozapine, unlike haloperidol, does not induce changes in striatal D-2 receptor function in the rat. Biochemical Pharmacol 34:2755-2763, 1985

16. Ljunberg $\mathrm{T}$, Ungerstedt $\mathrm{U}$ : Classification of neuroleptic drugs according to their ability to inhibit apomorphine-induced locomotion and gnawing: Evidence for two different mechanisms of action. Psychopharmacol 56:239-247, 1978

17. Costall B, Naylor RJ: Detection of the neuroleptic properties of clozapine, sulpiride and thioridazine. Psychopharmacol 43:69-74, 1975

18. Lai H, Carino MA, Sperry R, Horita A: Effects of thioridazine on apomorphineelicited stereotypic behavior and motor activity. Pharmacol Biochem Behav $13: 397-401,1980$

19. Vasse M, Protais P, Costentin J, Schwartz J-C: Unexpected potentiation by discriminant benzamide derivatives of stereotyped behaviours elicited by dopamine agonists in mice. Naunyn-Schmeidberg's Arch Pharmacol 329:108-1 16, 1985

20. Robertson A, MacDonald C: Opposite effects of sulpiride and metoclopramide on amphetamine-induced stereotypy. Eur J Pharmacol 109:81-89, 1985

21. Robertson A, MacDonald C: The effects of some atypical neuroleptics on apomorphine-induced behaviors as a measure of their relative potenices in blocking presynaptic versus postsynaptic dopamine receptors. Pharmacol Biochem Behav 24:1639-1643, 1986 
22. Conway P, Uretsky NJ: Enhanced stereotyped response to amphetamine after pretreatment with small doses of molindone. Neuropharmacol 22:579-586, 1983

23. DeVeaugh-Geiss J, Devanand DP, Carey RJ: Differential liabilities of haloperidol and thioridazine for inducing apomorphine hypersensitivity. Biol Psychiatry 17:1289-1301, 1982

24. Meller E: Chronic molindone treatment: relative inability to elicit dopamine receptor supersensitivity in rats. Psychopharmacol 76:222-227, 1982

25. Koller W, Curtin J, Fields J: Molindone compared to haloperidol in a Guinea-Pig model of tardive dyskinesia. Neuropharmacol 23:1 191-1194, 1984

26. Jenner P, Rupniak NMJ, Marsden CD: Differential alteration of striatal D-1 and D-2 receptors induced by the long-term administration of haloperidol, sulpiride, or clozapine to rats. Psychopharmacol Suppl 2:174-181, 1985

27. Bannet J, Gillis S, Ebstein RP, Belmaker RH: Effect of chronic sulpiride on striatal spiperone binding. Int Pharmacopsychiat 15:334-337, 1980

28. Klawans H, Rubovits R: Effect of cholinergic and anticholinergic agents in tardive dyskinesia. J Neurol Neurosurg Psychiatry 27:941-949, 1974

29. Tarsy D, Baldessarini RJ: Pharmacologically-induced behavioral super-sensitivity to apomorphine. Nature 245:262-263, 1973

30. Gerlach J: Pathophysiological mechanisms underlying tardive dyskinesia. Psychopharmacol Suppl 2:98-103, 1985

31. Cross AJ, Crow TJ, Ferrier IN, et al: Chemical and structural changes in the brain in patients with movement disorder. Psychopharmacol Suppl 2:104-110, 1985

32. Walters JR, Lanthorn TH, Waszczak BL, Baring MD, Knight M, Steardo L: Modulation of midbrain dopamine cell activity, in Catecholamines: Neuropharmacology and Central Nervous System-Theoretical aspects. New York, Alan R. Liss, Inc., 1984

33. Chiodo LA, Bunney BS: Typical and atypical neuroleptics: Differential effects of chronic administration on the activity of A9 and A10 midbrain dopaminergic neurons. J Neurosci 8:1607-1610, 1983

34. Freeman AS, Bunney BS: Chronic neuroleptic effects on dopamine neuron activity: A model for predicting therapeutic efficacy and side effects?, in Clinical Pharmacology in Psychiatry. Edited by Dahl SG, Gram LF, Paul SM, Potter WZ. New York, Springer-Verlag, 1987

35. Fibiger HS, Lloyd KG: Neurobiological substrates of tardive dyskinesia: the GABA hypothesis. Trends Neurol Sci 7:462-464, 1984

36. Doudet D, Bioulac-Sage P, Arluison M, et al: Neurobiological changes induced by neostriatal kainic acid injection: An electrophysiological and morphological approach to the physiopathology of Huntington's chorea, in The Basal Ganglia. Edited by McKenzie JS, Kemm RE, Wilcock LN. New York, Plenum Press, pp 405-430, 1984

37. Domino EF: Induction of tardive dyskinesia in Cebus appella and Macaca speciosa monkeys: A review, in Dyskinesia-Research and Treatment (Psychopharmacology Supplementum 2). Edited by Casey DE, Chase TN, Christensen AV, Gerlach J. New York, Springer-Verlag, 1985

38. Gunne L-M, Haggstrom J-E, Sjoquist B: Association with persistent neurolepticinduced dyskinesia of regional changes in brain GABA synthesis. Nature 309:347349,1984

39. White FJ, Wang RY: Differential effects of classical and atypical antipsychotic drugs on A9 and A10 dopamine neurons. Science 221:1054-1056, 1983 
40. Chiodo LA, Bunney BS: Possible mechanisms by which repeated clozapine administration differentially affects the activity of two subpopulations of midbrain dopamine neurons. J Neurosci 5:2539-2544, 1985

41. Bunney BS, Roth RH, Aghajanian GK: Effects of molindone on central dopaminergic neuronal activity and metabolism: Similarity to other neuroleptics. Psychopharmacol Comm 1:349-358, 1975

43. Guidotti A, Gale K, Tofano G, Vargas FM: Tolerance to tyrosine hydroxylase activation in N. Accumbesn and C. Striatum after repeated injection of "classical" and "atypical" antischizophrenic drugs. Life Sci 23:501-506, 1978

44. Walters JR, Roth RH: Dopaminergic neurons: An in vivo system for measuring drug interactions with presynaptic receptors. Arch Pharmacol 296:5-14, 1976

45. Herrera-Marschitz M, Stahle L, Tossman U, Zetterstrom T, Ungerstedt U: Behavioural and biochemical studies with the benzamide sulpiride in rats. Acta Psychiatr Scand 311:147-162, 1984

46. Richelson E: Neuroleptics and neurotransmitter receptors. Psychiatry Annals 10:21-40, 1980

47. Hyttel J, Larsen J-J, Christensen AV, Arnt J: Receptor-binding profiles of neuroleptics, in Dyskinesia-Research and Treatment (Psychopharmacology Supplementum 2). Edited by Casey DE, Chase TN, Christensen AV, Gerlach J. New York, Springer-Verlag, 1985

50. Morgenstern R, Fink H, Oelssner W: LSD-potentiated apomorphine hypermotility: A model for differentiating anti-psychotic drugs. Pharmacol Biochem Behav 18:13-17, 1983

51. Geyer MA, Puerto A, Dawsey WJ, Knapp S, Bullard WP, Mandell AJ: Histologic and enzymatic studies of the mesolimbic an mesostriatal serotonergic pathways. Brain Res 106:241-256, 1976

52. Roth RH: CNS dopamine autoreceptors: Distribution, pharmacology, and function. Ann NY Acad Sci 430:27-89, 1984

53. DiChiara G, Corsini GU, Mereu GP, Tissari A, Gessa GL: Self-inhibitory dopamine receptors: Their role in the biochemical and behavioral effects of low doses of apomorphine. Adv Biochem Psychopharmacol 19:275-291, 1978

54. Anden N-E, Alander T, Gabowska-Anden M, et al: The pharmacology of pre- and postsynaptic dopamine receptors: Differential effects of dopamine recptor agonists and antagonists, in Catecholamines: Neuropharmacology and Central Nervous System-Theoretical Aspects. New York, Alan R Liss, Inc., 1984

55. Fuller RW, Snoddy HD: Molindone: Higher doses needed to block pergolideinduced elevation of serum corticosterone than to elevate dopamine metabolites in brain. Life Sci 13:2357-2361, 1983

56. Alander T, Grabowska-Anden M, Anden N-E: Physiological significance of dopamine autoreceptors as studied following their selective blockade by molindone. J Pharm Pharmacol 32:780-782, 1980

57. Kendler KS, Bracha HS, Davis KL: Dopamine autoreceptor and postsynaptic receptor blocking potency of neuroleptics. Eur J Pharmacol 79:217-223, 1982

58. Sumners C, deVries JB, Horn AS: Behavioral and neurochemical studies on apomorphine-induce hypomotility in mice. Neuropharmacol 20:1203-1208, 1981

59. Gonon FG, Buda MJ: Regulation of dopamine release by impulse flow and by autoreceptors as studied by in vivo voltammetry in the rat striatum. Neurosci 14:765-774, 1985

60. Bannon MJ, Reinhard JF, Bunney EB, Roth RH: Unique response to antipsychotic 
drugs is due to absence of terminal autoreceptors in mesocortical dopamine neurones. Nature 296:444-446, 1982

61. Bannon MJ, Wolf ME, Roth RH: Pharmacology of dopamine neurons innervating the prefrontal, cingulate, and piriform cortices. Eur J Pharmacol 91:119-125, 1983

62. Carnoy P, Sooubrie P, Puech AJ, Simon P: Performance deficit induced by low doses of dopamine agonists in rats: Toward a model for approaching the neurobiology of negative schizophrenic symtpomatology? Biol Psychiatry 21:11-22, 1986

63. Meltzer HY: Relevance of dopamine autoreceptors for psychiatry: Preclinical and clinical studies. Schiz Bull 6:456-475, 1980

64. Willner P: Dopamine and depression: A review of recent evidence. I. Empirical Studies. Brain Res Rev 6:211-224, 1983

65. Willner P: Dopamine and depression: A review of recent evidence. II. Theoretical approaches. Brain Res Rev 6:225-236, 1983

66. Willner P: Dopamine and depression: A review of recent evidence. III. The effects of antidepressant treatments. Brain Res Rev 6:237-246, 1983

66. Baldessarini RJ: Clinical and epidemiologic aspects of tardive dyskinesia. J Clin Psychiatry 46:8-13, 1985

67. Povlson UJ, Noring U, Fog R, Gerlach J: Tolerability and therapeutic effect of clozapine. Acta psychiatr scand 71:176-185, 1985

68. Claghorn JL, Abuzzahab FS, Wang R, Larson C, Gelenberg AJ, Klerman GL, Tuason V, Steinbook R: The current status of clozapine. Psychopharmacol Bull 19:138-140, 1983

69. Gunne LM, Barany S: A monitoring test for the liability of neuroleptic drugs to induce tardive dyskinesia. Psychopharmacol 63:195-198, 1979

70. Gerlach J, Simmelsgaard H: Tardive dyskinesia during and following treatment with haloperidol, haloperidol, biperiden, thioridazine, and clozapine. Psychopharmacol 59:105-112, 1978

71. Gerlach J, Thorsen K, Fog R: Extrapyramidal reactions and amine metabolites in cerebrospinal fluid during haloperidol and clozapine treatment of schizophrenic patients. Psychopharmacol 40:341-350, 1975

72. Glazer WH, Hafez HM, Banarroche CL: Molindone and haloperidol in tardive dyskinesia. Moban symposium proceedings, 1985

73. Casey DE, Gerlach J and Simmelsgaard H: Sulpiride in tardive dyskinesia. Psychopharmacol 66:73-77, 1979

74. Quinn N, Marsden CD: A double blind trial of sulpiride in Huntington's disease and tardive dyskinesia. J Neurol Neurosurg and Psychiat 47:844-847, 1984

75. Haggstrom JE: Effects of sulpiride on persistent neuroleptic-induced dyskinesia in monkeys. Acta Psychiatr Scand [Suppl] 311:103-108, 1984

76. Kovacic B, Ruffing D, Stanley M: Effect of neuroleptics and of potential new anti-psychotic agents (MJ 13859-1 and MJ13980-1) on a monkey model of tardive dyskinesia. J Neural Transmission 65:39-49, 1986

77. Opler LA, Kay SR, Rosado V, Lindenmayer J-P: Positive and negative syndromes in chronic schizophrenic inpatients. J Nerv Mental Disord 172:317-325, 1984

78. Meltzer HY: Effect of neuroleptics on the schizophrenic syndrome, in Clinical Pharmacology in Psychiatry. Edited by Dahl SG, Gram LF, Paul SM, Potter WZ. New York, Springer-Verlag, 1987

79. Kay SR, Fiszbein A, Opler LA: The positive and negative syndrome scale (PANSS) for schizophrenia. Schiz Bull 13:261-275, 1987 
80. Andreassen NC: Negative symptoms in schizophrenia: Definition and reliability. Arch Gen Psychiatry 39:784-788, 1982

81. Overall JE, Gorham DR: Brief psychiatric rating scale. Psychological Reports 10:799-812, 1962

82. Opler LA, Kay SR, Fiszbein A: Positive and negative syndromes in schizophrenia: Typological, dimensional, and pharmacological validation, in Positive and Negative Symptoms in Psychosis: Description, Research and Future Directions. Edited by Harvey PD, Walker E, Hillsdale, NJ, Lawrence Erlbaum Associates Inc., 1986

83. Shopsin B, Klein H, Aaronsom M, Collora M: Clozapine, chlorpromazine, and placebo in newly hospitalized, acutely schizophrenic patients. Arch Gen Psychiatry 36:657-664, 1979

84. Gerlach J, Koppelhaus P, Helweg E, et al: Clozapine and haloperidol in a singleblind cross-over trial: Therapeutic and biochemical aspects in the treatment of schizophrenia. Acta Psychiatr Scand 50:410-424, 1974

85. Gellenberg AJ, Doller JC. Clozapine versus chlorpromazine for the treatment of schizophrenia: Preliminary results from a double-blind study. J Clin Psychiatry 40:238-240, 1979

86. Chouinard G, Annable L: Clozapine in the treatment of newly admitted Schizophrenic patients. J Clin Pharmacol 289-297, 1976

87. Fischer-Cornellssen K, Ferneer J. An example of European multicenter trials: Multispectral analysis of clozapine. Psychopharmacol Bull 12:34-39, 1976

88. Clark ML, Huber WK, Charalampous KD, Serfetinides EA, Trousdale W, Colmore JP. Drug treatment in newly admitted schizophrenic patients. Arch Gen Psychiatry 25:404-409, 1971

89. Vital-Herne J, Gerbino L, Kay SR, Katz IR, Opler LA: Mesoridazine and thioridazine: Clinical effects and blood levels in refractory schizophrenics. J Clin Psychiatry 47:375-379, 1986

90. Sugerman AA: Comparison of TPS-23 and thioridzine in chronic schizophrenic patients. Curr Ther Res 7:520-527, 1965

91. Ritter RM, Tatum PA: Two studies of the effects of mesoridazine. J Clin Pharmacol 12:349-355, 1972

92. Freeman H: A double-blind comparison of mesoridzine and chlorpromazine in chronic schizophrenics. Dis Nerv Sys 34:289-293, 1973

93. Freeman H, Oktem MR, Oktem N: A double-blind comparison of the therapeutic efficacy of mesoridazine versus chlorpromazine. Curr Ther Res 11:263-270, 1969

94. Melke DH, Gallant DM, Roniger JJ, Kessler C, Kessler IR: Sulpiride: Evaluation of antipsychotic activity in schizophrenic patients. Dis Nerv Sys 569-571, 1977

95. Rama Rao VA, Bailey J, Bishop M, Coppen A: A clinical and pharmacodynamic evaluation of sulpiride. Psychopharmacol 73:77-80, 1981

96. Munk-Andersen E, Behnke K, Heltberg J, Hielsen H, Gerlach J: Sulpiride versus haloperidol, a clinical trial in schizophrenia: A preliminary report. Acta Psychiatr Scand Suppl 2:31-39, 1983

97. Alfredson G, Harnryd C, Wiesel F-A: Effects of sulpiride and chlorpromazine on autistic and positive psychotic symptoms in schizophrenic patients-relationship to drug concentrations. Psychopharmacol 85:8-13, 1985

98. Elizur A, Davidson S. The evaluation of the anti-autistic activity of sulpiride. Curr Ther Res 18:578-584, 1975

99. Nishiura M: Clinical-pharmacological studies of sulpiride. Curr Ther Res 20:164169,1976 
100. Gallant DM, Bishop MP: Molindone: A controlled evaluation in chronic schizophrenic patients. Curr Ther Res 10:441-447, 1968

101. Binder RE, Glick I, Rice M: A comparative study of parenteral molindone and haloperidol in the acutely psychotic patient. J Clin Psychiatry 42:203-206, 1981

102. Simpson GM, Amin M, Edwards JG: A double-blind comparison of molindone and trifluoperazine in the treatment of acute schizophrenia. J Clin Pharmacol 11:227236, 1971

103. Turek IS, Ota KY, DeLaRocha M, et al: The use of molindone in the treatment of acute psychotic states: comparison of two dose schedules. J Clin Pharmacol 10:349-355, 1970

104. Clark ML, Huber WK, Sakate K, et al: Molindone in chronic schizophrenia. Clin Pharmacol Ther 11:680-688, 1970

105. Freeman H, Frederick AND: Comparison of trifluoperazine and molindone in chronic schizophrenic patients. Curr Ther Res 11:670-676, 1969

106. Ramsay RA, Ban TA, Lehman HE, et al: Comparative study of molindone and trifluoperazine. Curr Ther Res 12:438-440, 1970 